\title{
TEXTURE DEVELOPMENT IN A HOT-ROLLED RAPIDLY-QUENCHED AL-CR-FE ALLOY
}

\author{
A W BOWEN and C J GILMORE \\ Materials and Structures Dept., Royal Aerospace Establishment , Farnborough, Hants \\ GU14 6TD UK
}

\section{INTRODUCTION}

Rapid-solidification processsing of aluminium alloys not only permits the extension of solid solubility limits and the formation of metastable phases, but can also produce non-random textures (eg ref 1). Of the many techniques available, that of evaporation-condensation has been the preferred route in the Royal Aerospace Establishment, where aluminium-transition metal alloys containing considerable degrees of supersaturation have been produced in bulk.

The microstructural characteristics and mechanical properties of these alloys have already been reported ${ }^{2-12}$. The purpose of the present paper is to describe the type of nonrandom texture developed in a rapidly-quenched $\mathrm{Al}-\mathrm{Cr}-\mathrm{Fe}$ alloy deposited from the vapour, and to illustrate how this changes during a series of hot-rolling reductions to produce thin sheet suitable for aerospace applications.

\section{EXPERIMENTAL}

The alloy was produced from a bath of the correct composition, which was kept molten by scanning electron beams. The resultant vapour was then condensed onto a reciprocating temperature-controlled collector to produce a layered microstructure with the composition $\mathrm{Al}-8.5 \mathrm{wt} \% \mathrm{Cr}-1.2 \mathrm{wt} \% \mathrm{Fe}$. In this microstructure each layer, resulting from one pass over the source, is $\sim 75 \mu \mathrm{m}$ thick. The grains are columnar and $\sim 0.2-0.5 \mu \mathrm{m}$ wide 4 .

To produce material suitable for testing, a $9 \mathrm{~mm}$ thick plate was prepared from this deposit for hot rolling at $290^{\circ} \mathrm{C}$. Material for evaluation was taken at $0,20,30,60$ and $80 \%$ reductions (when the thickness was $\sim 1.7 \mathrm{~mm}$ ). Further details on the rolling of these alloys can be found in ref 13 .

Specimens for texture and microstructure analyses were then prepared, with the texture samples being polished to mid-thickness prior to the measurement of incomplete (maximum tilt $\left.=85^{\circ}\right)(111),(200),(220)$ and (311) pole figures. These figures were then processed using the series expansion method to produce three-dimensional orientation distribution functions ${ }^{14}$. 

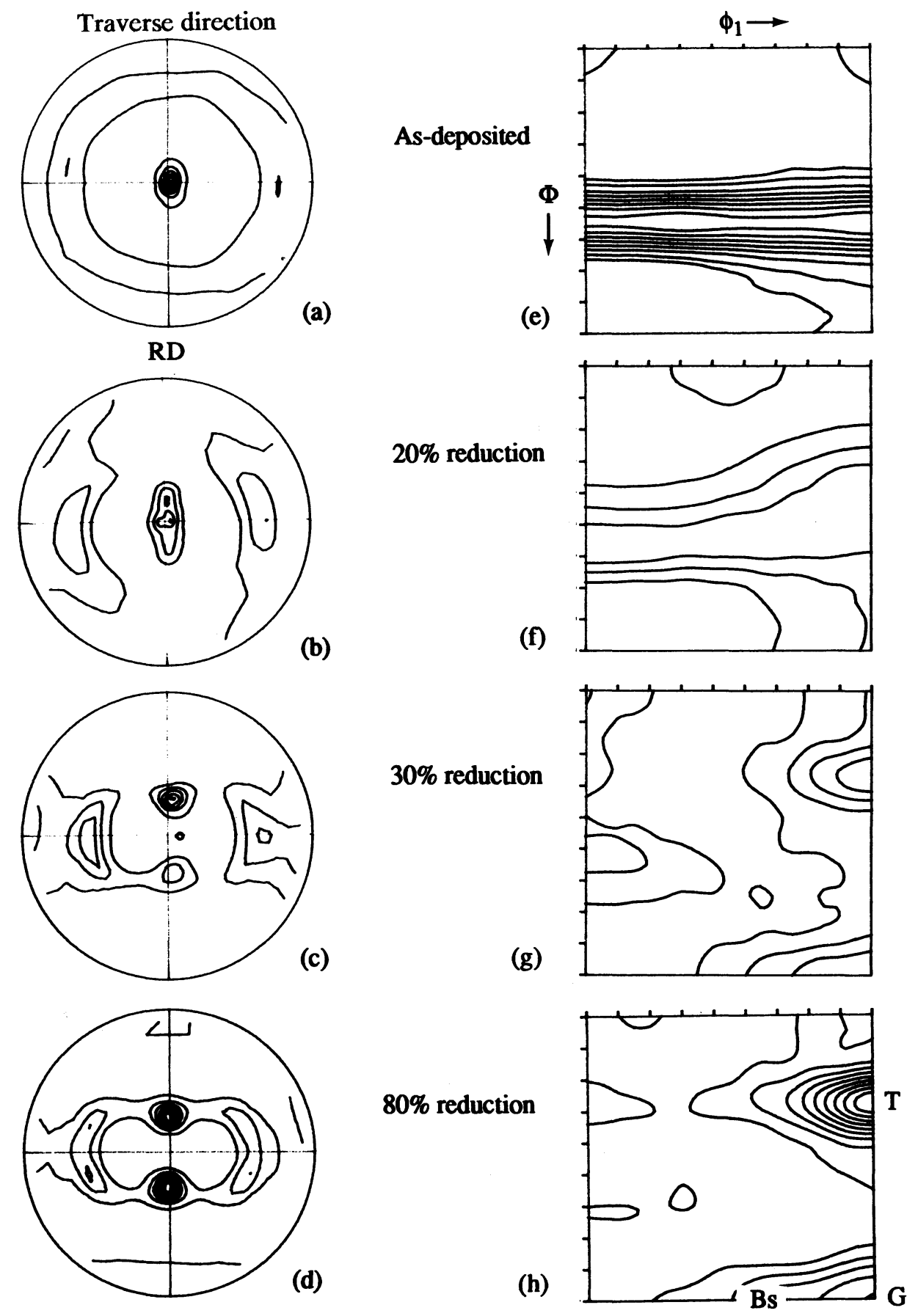

Figure 1. Experimental (111) pole figures (a-d) and $\phi_{2}=45^{\circ}$ sections (e-h) for the Al-Cr-Fe alloy in the as-deposited condition and after 20,30 and $80 \%$ reductions. Traverse direction refers to the direction of traverse of the collector during deposition. RD=Rolling Diection. Contours: $1,4,7,10,13,16,19$ for as-deposited pole figure; $1,2,4,6,8,10$ for as-deposited $\phi_{2}=45^{\circ}$ section; $1,2,3,4,5,6,7,8,9$ for all others. 


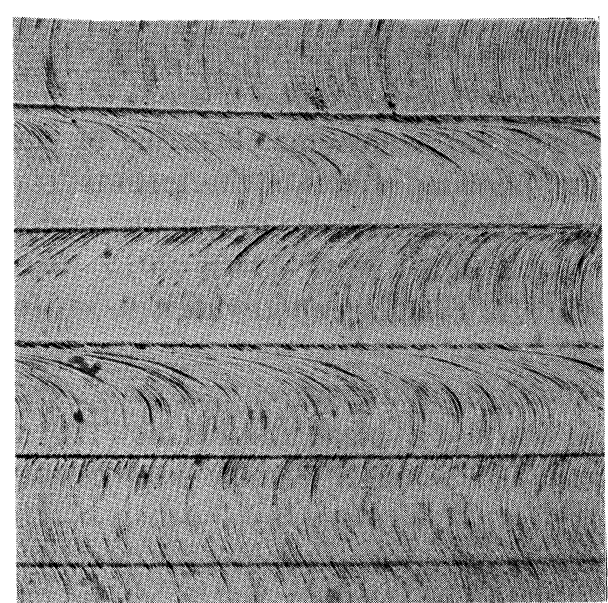

(a)

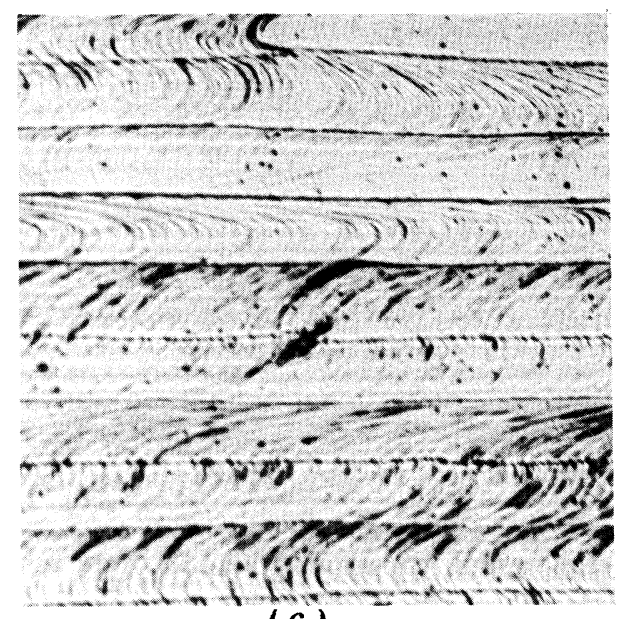
(c)

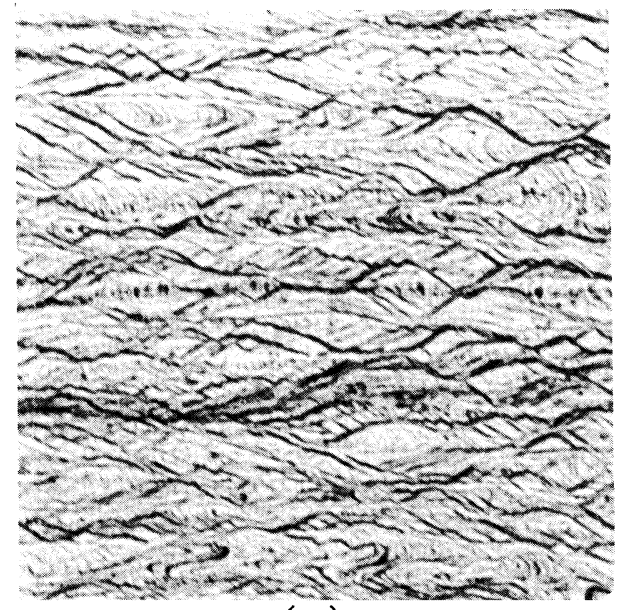

(e)

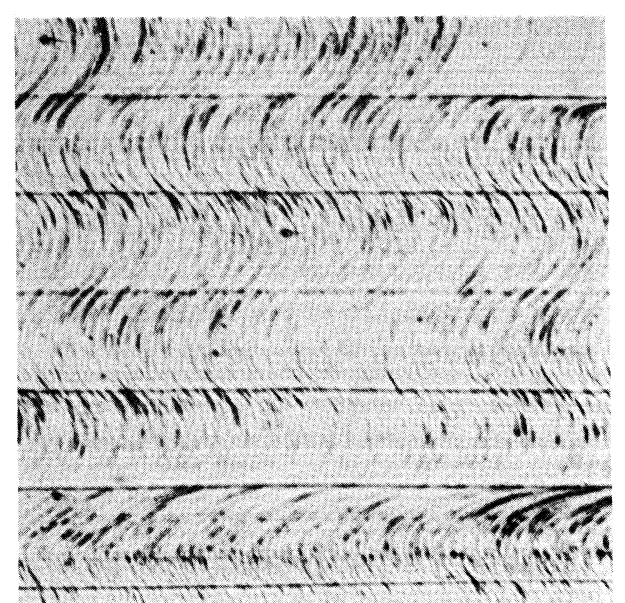

(b)

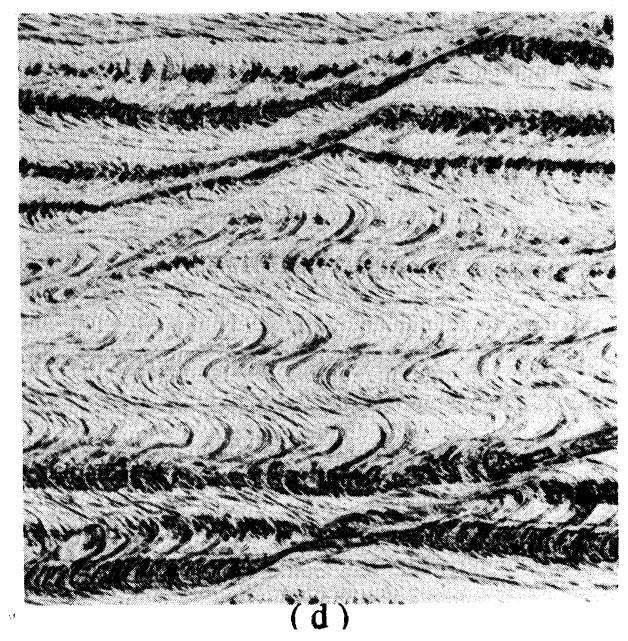

Fig. 2. Optical micrographs from the Al-Cr-Fe alloy in the

(a) as deposited condition and after
(b) $20 \%$ reduction
(c) $30 \%$ reduction
(d) $60 \%$ reduction
(e) $80 \%$ reduction 


\section{RESULTS}

Texture analysis showed that the as-deposited condition possessed a strong $<111>$ fibre texture in the growth (normal) direction (Figure 1a), with some clustering of intensity around $<112>$ (Figure 1e). Hot rolling had the following effects on this texture:

- After $20 \%$ reduction the intensity of the $<111>$ fibre was reduced by a quarter with a shift in the clustering from $<112>$ to $<110\rangle$. In addition, weak $\{110\}<001>$ (Goss-G), $\{4,4,11\}<8,8,11>$ (Taylor-T) and $\{123\}<634>$ (S) orientations were evident (most of which are indicated in Figure $1 \mathrm{~h})$.

- After $30 \%$ reduction the $<111>$ fibre texture had been removed and the T, G and $S$ orientations had increased in intensity. There was also a spread towards the $\{110\}<112>$ (Brass-Bs) orientation. The $\mathrm{T}$ orientation was $\sim 50 \%$ stronger than the other orientations (Figure $1 \mathrm{~g}$ ).

- After $60 \%$ reduction all three remaining orientations had almost doubled in intensity, with the $T$ orientation being twice as strong as the $G$ and $S$ orientations, and the spread towards the Bs orientation became more marked. Further rolling to $80 \%$ reduction (Figure $1 \mathrm{~h}$ ) produced no additional change in texture type or intensity.

Microscopy examination (Figure 2) showed evidence of extensive shear banding for all reductions greater than about $30-40 \%$, in agreement with earlier work ${ }^{13}$.

\section{DISCUSSION}

This investigation has shown that a rapidly-quenched $\mathrm{Al}-\mathrm{Cr}-\mathrm{Fe}$ alloy, prepared by vapour deposition, had an initial texture with the close-packed (111) planes parallel to the collector surface, and that hot rolling broke down this preferred orientation very quickly to produce textures that are not too dissimilar from those of conventional aluminium alloys ${ }^{15}$. To compare these experimental textures with those predicted by deformation theory ${ }^{16,17}$, the asdeposited condition has been represented by a total of 535 grains (within the angular range $\phi_{2}=35-55, \phi_{1}=0-90$ and $\Phi=45-65^{\circ}$ ) distributed along a tube of intensity centred on a $<111>$ fibre texture in the normal direction. Those represented in the $\phi_{2}=45^{\circ}$ section of the ODF are shown in Figure 3a. Deformation of this aggregate of grains to the equivalent of an $80 \%$ reduction according to full constraints and relaxed (in this case pancake grains) constraints theory, using the code of ref 17, gave the results in Figures $3 \mathrm{~b} \& \mathrm{c}$. These predictions show that the full constraints Taylor theory gives clustering around $\{4,4,11\}<8,8,11>$ (Figure $3 b)$, but that any relaxation to account for the Goss texture in Figures $1 \mathrm{~g}$ and $\mathrm{h}$ also shifts the Taylor orientation to that of copper $(\mathrm{Cu})$ at $\{112\}<111>$ (Figure $3 \mathrm{c}$ ). This is clearly not observed in practice (Figure 1h). However, if we take into account the initial unconventional microstructure and the microstructural changes shown in Figure 2, it is not unreasonable to assume that in practice each layer behaves as a series of pancake grains in the early stages of deformation, and would hence be under relaxed constraint, but that after a reduction of about $30-40 \%$, where shear bands begin to break up these pancake grains and force each grain to begin to act independently, grain behaviour then changes to the fully constrained condition. On this basis, if we re-evaluate the deformation of the idealised $<111>$ normal texture of Figure $3 \mathrm{a}$ in terms of relaxed (pancake) constraints to $30 \%$ reduction, followed by full constraints, this produces the textures in Figures $3 d-f$. Whilst in practice such a transition from relaxed to full constraints would be gradual, these predicted textures based on mixed constraints show the correct combinations of T, G, S and Bs orientations, and thus 

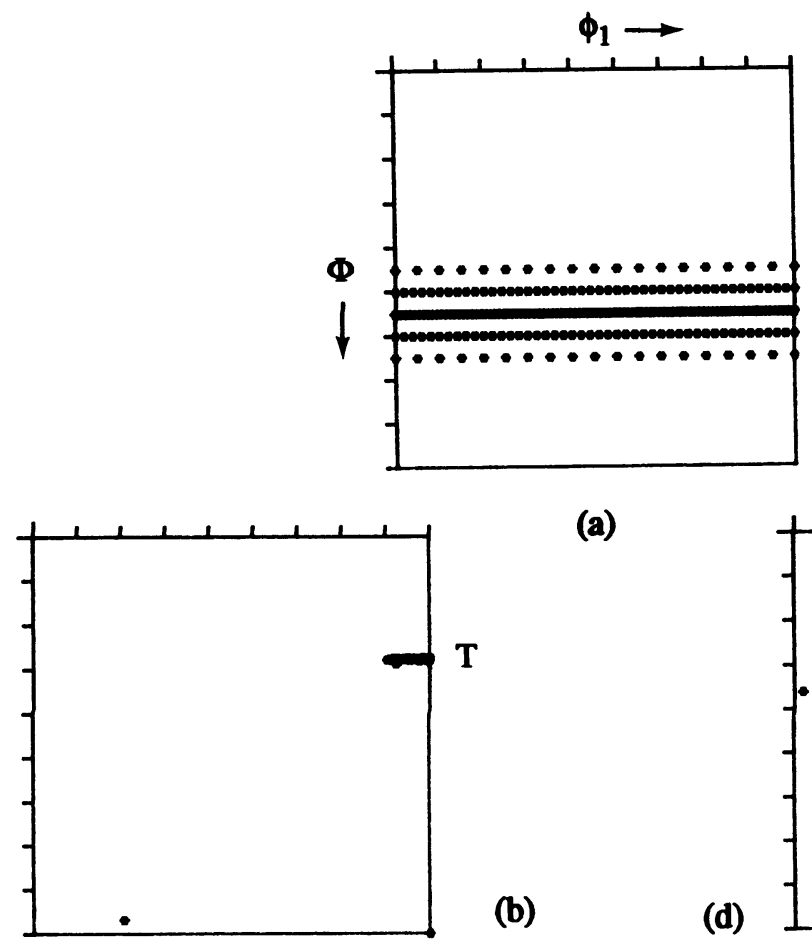

(a)

(b)

(d)
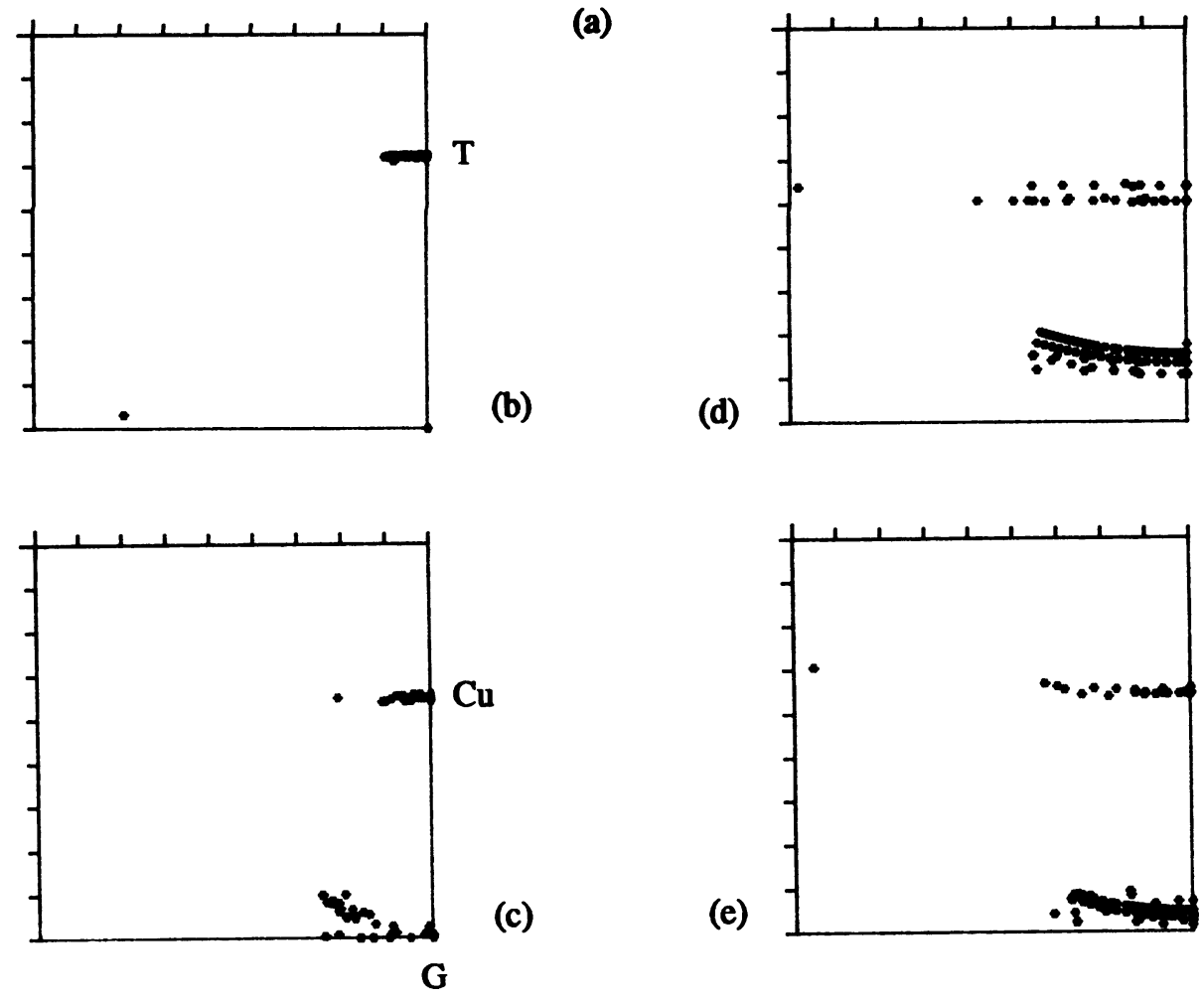

(e)

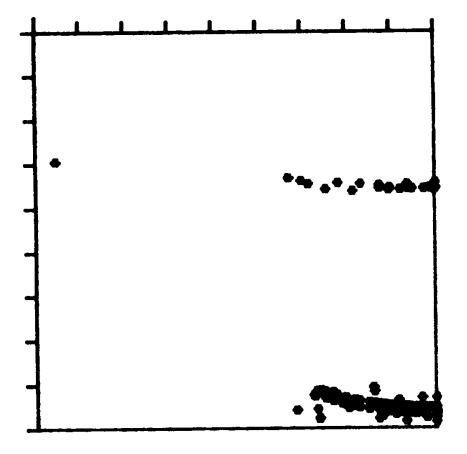

Figure 3. Grain orientations, shown in $\phi_{2}=45^{\circ}$ sections, for an idealised $\langle 111\rangle$ fibre texture in the normal direction (a); after an $80 \%$ reduction under full (b) and relaxed (pancake) (c) constraints; and after (d) $20 \%$, (e) $30 \%$, and (f) $80 \%$ reductions under mixed constraints. (See text for details).

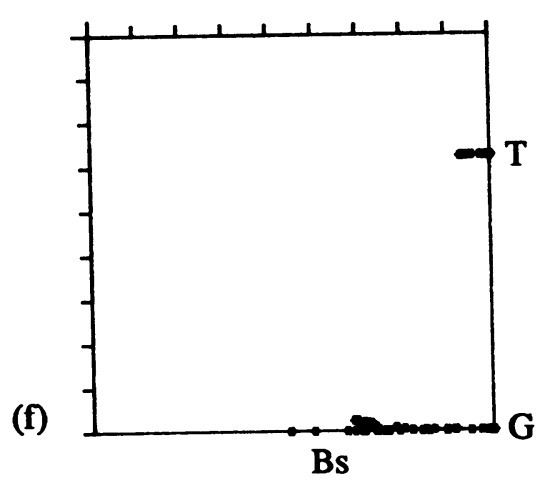


agree much more closely with the experimental textures of Figure 1 than those based only on relaxed or full constraints.

\section{CONCLUSIONS}

1. A layered vapour-deposited Al-Cr-Fe alloy had a strong $<111>$ fibre texture in the growth (normal) direction. The grain size was very fine.

2. Hot rolling at $290^{\circ} \mathrm{C}$ broke up the fibre texture resulting in a rolling texture consisting of the $T, S, G$ and Bs orientations.

3. Texture development could be explained if it was assumed that the alloy deformed under relaxed constraints during the initial rolling, because the layered structure behaved as a series of pancake grains, but changed to full constraints after about $30-40 \%$ reduction when the layered structure was broken up by shear bands.

\section{ACKNOWLEDGMENT}

The authors would like to thank Mrs S M Goodwin for assisting with preparation of the figures. () Controller, HMSO London 1990.

\section{REFERENCES}

1. S. Bergmann et al, in Proc 5th Int Conf on Textures of Materials (ed G Gottstein and K Lucke, Springer Verlag Berlin 1978) 351

2. C. J. Gilmore and A. W. Bowen, Nondestr .Test . \& Eval., 5, 379 (1990)

3. R. W. Gardiner, Mater. \& Design, 10, 274 (1989)

4. C. J. Gilmore and A. W. Bowen, Proc 9th European Congress on Electron Microscopy , Inst of Phys Conf Ser No. 93, 2, 199 (1988).

5. C. J. Gilmore and A. W. Bowen, Proc EMAG 89, Inst of Phys Conf Ser No. 98, 187 (1989)

6. R. L. Bickerdike et al, Int . J . Rapid Sol ., 1, 305 (1984-5)

7. R. L. Bickerdike et al, Int . J . Rapid Sol ., 2, 1 (1986)

8. M. D. McConnell and P. G. Partridge, Acta .Met ., 35, 1973 (1987)

9. P. G. Partridge and M. D. McConnell, ibid, 1981

10. P. G. Partridge, J . Mater . Sci,., 21, 3211 (1986)

11. B. A. Shollock, D. Phil. thesis, University of Oxford, 1989.

12. B. A. Shollock, submitted to Scripta . Met . \& Mater.

13. M. D. McConnell et al, RAE TR83074 (1983)

14. H. J. Bunge, Texture Analysis in Materials Science (Butterworths London 1982)

15. B. A. Riggs et al, Aluminum: Properties and Physical Metallurgy (Ed J. E. Hatch, ASM Metals Park Ohio 1984) 125

16. T. Lefers et al, in Proc 8th Int Conf on Textures of Materials (eds J. S. Kallend and

G. Gottstein , AIME, Warrendale, Pa . 1988) 265

17. R. Fortunier and J. Hirsch in Theoretical Methods in Texture Analysis (ed H. J.

Bunge, DGM, Oberursel 1987) 231 